\title{
RELAÇÃO DE DISCIPLINAS AMBIENTAIS NAS MATRIZES CURRICULARES DOS CURSOS TECNOLÓGICOS DA FATEC
}

\section{LIST OF ENVIRONMENTAL DISCIPLINES IN THE CURRICULAR MATRICES OF FATEC'S TECHNOLOGICAL COURSES}

\author{
Gian Lucas Ramalho Bonetti ${ }^{\mathrm{I}}$ \\ Douglas Leonardo Camargo Colucci ${ }^{\mathrm{II}}$ \\ Celso Luiz Franzotti ${ }^{\text {III }}$
}

\begin{abstract}
RESUMO
Este trabalho foi desenvolvido com a finalidade de verificar a adequação das matrizes curriculares dos cursos tecnológicos da FATEC (Faculdade de Tecnologia de São Paulo) como propõe a Política Nacional de Educação Ambiental - PNEA (Lei 9.795/1999). A PNEA dispõe sobre sua conceituação, princípios, objetivos e disposições da aplicação dos temas ambientais nas instituições ensino. A FATEC é uma instituição de ensino superior do estado de São Paulo presente em 66 cidades do interior e litoral do estado mais a Capital. A verificação se deu por meio de uma análise das matrizes curriculares dos 77 cursos tecnológicos atualmente ministrados nos campi da FATEC, que objetivou identificar quais cursos possuem em sua matriz curricular a disciplina de Gestão Ambiental e/ou outras disciplinas correlacionadas ao tema. Também foi levantado quais temas ambientais são abordados nas ementas dos cursos e a inserção da gestão ambiental nos eixos tecnológicos que classificam os campos de atuação dos cursos ministrados na FATEC. Como resultado obteve-se a distribuição dos cursos que apresentam ao menos uma disciplina de gestão ambiental em sua grade, bem como a distribuição deste contexto nos eixos tecnológicos.
\end{abstract}

Palavras-chave: Temática Ambiental. Ementa Curricular. Formação Ambiental.

\begin{abstract}
This work was developed with the purpose of verifying the adequacy of the curricular matrices of the technological courses of the FATEC (Faculty of Technology of São Paulo) as proposed by the national Policy of Environmental Education-PNEA (Lei 9.795/1999). PNEA has on its conceptuation, principles, objectives and provisions of the application of environmental issues in teaching institutions. FATEC is a higher education institution in the state of São Paulo present in 66 cities in the countryside and the state's coastline plus the Capital. The verification was made through an analysis of the curricular matrices of the 77 technological courses currently taught on the campuses of FATEC, which aimed to identify which courses have in their curriculum matrix the discipline of environmental management

I Estudante do curso superior de Tecnologia em Mecânica: processos de soldagem da Faculdade de Tecnologia (FATEC) de Sertãozinho - São Paulo - Brasil. E-mail:geanlucasramalho@gmail.com

${ }^{\text {II }}$ Estudante do curso superior de Tecnologia em Mecânica: processos de soldagem da Faculdade de Tecnologia (FATEC) de Sertãozinho - São Paulo - Brasil. E-mail. douglascolucci.eng @ gmail.com

III Prof. Dr. da Faculdade de Tecnologia (FATEC) de Sertãozinho - São Paulo - Brasil. E-mail: celso.franzotti@fatec.sp.gov.br
\end{abstract}




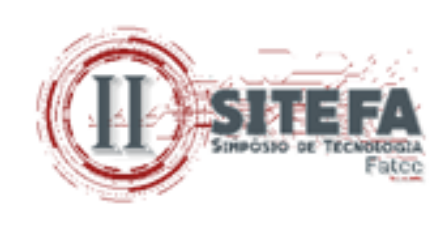

and/or other Subject-related disciplines. It was also raised which environmental issues are addressed in the course menus and the insertion of environmental management in the technological axes that classify the fields of action of the courses taught at FATEC. As a result we obtained the distribution of courses that present at least one discipline of environmental management in its grid, as well as the distribution of this context in the technological axes.

Keywords: Environmental thematic. Curricular menu. Environmental training.

Data de submissão do artigo: 14/07/2019.

Data de aprovação do artigo: 18/09/2019.

DOI:

\section{INTRODUÇÃO}

Os tópicos relacionados ao gerenciamento do meio ambiente e de seus recursos naturais não são recentes. No entanto, os mesmos adquiriram uma maior visibilidade nas últimas três décadas, incluindo as conferências ambientais como a Eco-92 a Conferência das Nações Unidas sobre o Meio Ambiente e o Desenvolvimento realizada no Rio de Janeiro em 1992, a Rio+10 ou Cúpula Mundial sobre o Desenvolvimento Sustentável, foi um evento organizado pela Organização das Nações Unidas (ONU) para discutir sobre as questões ambientais, realizada em Joanesburgo, na África do Sul em 2002 e a RIO + 20 a Conferência das Nações Unidas sobre Desenvolvimento Sustentável realizada em 2012 no Rio de Janeiro.

Assim, somente a poucas décadas, a ciência e a sociedade começam a dar a importância em conciliar o desenvolvimento industrial com o equilíbrio ecológico o que não era abordado com a devida relevância. Contudo, atualmente, sabe-se que o meio ambiente é um aliado da competividade industrial. Neste contexto, uma série de condicionamentos históricos induziu o homem a reavaliar seu modo de conduzir o modelo de crescimento econômico, o qual, até então, vinha relegando a um segundo plano as questões socioambientais (SEIFFERT, 2014).

O aumento da produção e do consumo, impactados pela Revolução Industrial, resultou na intensificação dos problemas socioambientais. Nesse cenário, as industriais atuam como principal foco desta poluição, gerando resíduos oriundos de embalagens e produtos, emissões de gases e efluentes e também transformando a agricultura e a pesca em atividades intensivas. Se por um lado tais intensificações dão um maior suporte ao consumo, por outro lado contribui para o aumento do lixo doméstico e comercial. Em outras palavras, as empresas desempenham um papel fundamental para a globalização dos problemas ambientais (BARBIERI, 2016).

Diante da importância atual do contexto ambiental inserido no dia à dia da sociedade e por consequência nas organizações, é importante que durante a graduação os alunos de diferentes cursos com diferentes campos de atuação recebam em suas grades curriculares disciplinas de cunho ambiental tal como a gestão ambiental e disciplinas correlatas para que possam atuar profissionalmente sabendo como proceder com os possíveis aspectos e impactos ambientais das atividades desenvolvidas em seu local de trabalho.

Assim o desenvolvimento do trabalho buscou-se, por meio de uma pesquisa exploratória, identificar quais cursos ministrados nos campi da FATEC, possuem disciplinas relacionadas a gestão ambiental; quais são os eixos temáticos relacionados a tais cursos e 


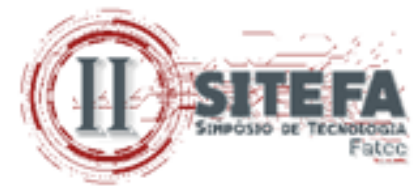

quais são as palavras chave relacionadas a temática ambiental mais são citadas nas ementas dos cursos.

\section{A QUESTÃO AMBIENTAL}

A questão ambiental tem sido um tema muito discutido, ao longo das últimas décadas, se atentando à preocupação na conservação dos recursos naturais e com a degradação provocada pelas ações antrópicas no meio ambiente (DRUZZIAN; SANTOS, 2006).

Disciplinas da temática ambiental segundo a PNEA, deveriam estar presentes nas grades curriculares de todos os cursos superiores, pois a maioria destes formam profissionais que irão exercer atividades em organizações que em maior ou menor grau poderão causar impactos no meio ambiente. Cabem as Instituições de Ensino Superior (IES) estabelecerem mecanismos para a inserção de disciplinas de temática ambiental no contexto de seus cursos. Segundo Rodrigues, Oliveira e Pilatti (2007), as Instituições de Ensino Superior no Brasil possuem ainda muitas dificuldades e obstáculos para inserir a dimensão ambiental à formação de recursos humanos, devido a alguns fatores tais como a forma de abordagem da questão ambiental setorial e multidisciplinar e o uso estudos de caráter técnicos, em detrimento dos aspectos epistemológicos e metodológicos. Mesmo assim Mayor (1998) cita que a educação é a chave do desenvolvimento sustentável. Uma educação fornecida à sociedade com base no uso de novas metodologias de ensino auxiliadas a novas e tecnologias beneficiam todos para um futuro mais sustentável. E ressalta ainda que escolas e universidades não são apenas lugares para se aprender teoricamente sobre desenvolvimento sustentável, mas lugares para se praticar ações de desenvolvimento sustentável.

\subsection{Educação ambiental}

A educação ambiental é uma ferramenta de extrema importância para a formação e conscientização das pessoas em relação as questões e problemáticas ambientais atuais pelas quais o planeta é impactado.

A ferramenta de caráter legal que trata da Educação Ambiental atualmente é Política Nacional de Educação Ambiental - PNEA (Lei 9.795/1999) que dispõem sobre sua conceituação, princípios, objetivos e disposições da aplicação dos temas ambientais nas instituições de ensino (BRASIL, 1999).

\footnotetext{
Em seu Art. número 1 a PNEA define o entendimento por educação ambiental como sendo os processos por meio dos quais o indivíduo e a coletividade edificam valores sociais, conhecimentos, habilidades, atitudes e competências voltadas para a conservação do meio ambiente, bem de uso comum do povo, essencial à sadia qualidade de vida e sua sustentabilidade. (BRASIL, 1999).
}

No caso das instituições de ensino, a mesma em seu Art. número 3, inciso III estabelece que se incumbe as instituições de ensino educativas, promover a educação ambiental de maneira integrada aos programas educacionais que desenvolvem.

No caso de instituições e ensino superior IES o Art. número 9, inciso II estabelece que a educação ambiental deve ser desenvolvida no âmbito da educação superior.

Uma outra referência em educação ambiental muito importante em nível mundial é a Agenda 21 a qual propõe um programa global de ações ambientalmente corretas, e que utilizam como base a conscientização, dando respaldo ao desenvolvimento sustentável. 


\begin{abstract}
No seu capítulo 36, a Agenda 21 define Educação Ambiental como sendo o processo formativo que coopera para desenvolver uma população que seja conscientizada e preocupada com o meio ambiente e com os problemas relacionados a estes, formando e informando a população para que tenha conhecimentos, habilidades, atitudes, motivações e compromissos para atuarem, individual e coletivamente, na procura de soluções para os problemas existentes e na prevenção dos problemas ambientais potenciais de uma dada região.
\end{abstract}

A carta de Belgrado segundo Barbieri (2004) define os temas centrais da educação ambiental como:

- Conscientização: busca contribuir para que indivíduos e grupos adquiram consciência e sensibilidade em relação ao meio ambiente como um todo e quanto aos problemas relacionados a ele.

- Conhecimento: propicia uma compreensão básica sobre o meio ambiente, principalmente quanto às influências do ser humano e de suas atividades.

- Atitudes: propiciar a aquisição de valores e motivação para induzir uma participação ativa na proteção ao meio ambiente e na resolução dos problemas ambientais;

- Habilidades: Proporcionar condições para que os indivíduos e grupos sociais adquiram as habilidades necessárias a essa participação ativa.

- $\quad$ Capacidade de avaliação: estimular a avaliação das providências efetivamente tomadas em relação ao meio ambiente e aos programas de educação ambiental;

- $\quad$ Participação: contribuir para que os indivíduos e grupos desenvolvam o senso de responsabilidade e de urgência com respeito às questões ambientais.

Desta forma constata-se que é de suma importância que temas ambientais estejam presentes nos diversos cursos de todas as áreas do conhecimento.

\title{
2.2 Gestão ambiental
}

A gestão ambiental segundo Barbieri (2016) define conceitos e padrões administrativos e de controle para serem aplicados nas atividades, processos e serviços que sejam potencialmente impactantes do meio ambiente. A gestão ambiental deve estar presente em todas as fases de uma organização, desde seu planejamento, construção, operação e desativação.

Moreira (2013) destaca que os sistemas de gestão da qualidade (SGQ), buscam a partir da identificação das reais necessidades dos clientes, a contínua melhoria e racionalização de projetos, processos e produtos/serviços. Dentro do contexto ambiental a série de normas ISO 14000 , focam na gestão da organização no produto/processo e no desempenho ambiental. Tachizawa (2015) cita que a norma de certificação ambiental NBR ISO 14001:2015 está contida no enfoque da organização, e é a principal norma de Gestão Ambiental da atualidade servindo como um instrumento para implantação de um sistema de gestão ambiental (SGA) na organização.

Segundo Moura (2011) a gestão ambiental e a responsabilidade social, tornam-se importantes instrumentos gerenciais para capacitação e criação de condições de competitividade para as organizações, qualquer que seja seu segmento econômico. Ainda segundo Fernandes (2009) a gestão ambiental é um importante instrumento de gestão de negócios garante uma capacitação e criação de condições de competitividade organizacional 


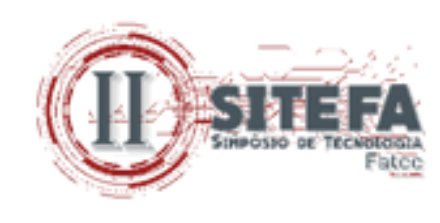

para reduzir e controlar seus impactos ambientais, qualquer que seja seu segmento econômico. Cabe a organização sempre analisar os efeitos que esta terá sobre a comunidade na sua circunvizinhança, monitorando temas tais como, consumo de água, energia, matéria prima, mão de obra e geração de resíduos. Segundo a ABNT: NBR ISO 14001:2015 o sistema de gestão ambiental de uma organização deve entender o seu contexto por meio das questões internas e externas que irão influenciar o desempenho ambiental da organização, ou entender como suas atividades, processos, aspectos e impactos estão relacionados, além disso a organização deve entender o que pensa e o que se espera da organização as partes interessadas com relação ao meio ambiente. A partir destas informações é que a organização estabelece o seu sistema de gestão ambiental.

Daí a importância de que os conhecimentos dos princípios da gestão ambiental são necessários na formação universitária independente da área, pois de modo geral todas atividades profissionais sempre poderão com maior ou menor potencial, impactar o meio ambiente.

\section{PROCEDIMENTOS METODOLÓGICOS}

Na primeira etapa foi realizado o levantamento, por meio dos sites e homepages, de todos os cursos ministrados nos campi da FATEC, distribuídas no estado de São Paulo. Após isto foi realizado a análise das matrizes curriculares dos cursos inseridas em seus projetos pedagógico, tal análise visou a identificação de quais delas apresentam disciplinas de gestão ambiental ou correlata. A próxima etapa foi a realização de uma análise minuciosa de cada uma das ementas das disciplinas de gestão ambiental ou correlata.

$\mathrm{Na}$ etapa de resultados foram elaboradas planilhas e gráficos para verificação das particularidades na abordagem da gestão ambiental nos diferentes eixos temáticos e nas disciplinas ministradas na FATEC, também foi realizada uma análise dos temos ambientais contidos nas ementas por meio da geração de uma nuvem de palavras que possibilitou identificar os termos mais citados nas ementas das disciplinas ambientais da FATEC.

\section{RESULTADOS E DISCUSSÃO}

Inicialmente foram identificados os cursos que possuíam disciplinas com a temática da Gestão Ambiental ou disciplinas correlatas e os cursos que não possuíam qualquer disciplina relacionada a gestão ambiental. Os resultados estão apresentados na Tabela 1 - Cursos como disciplinas de Gestão Ambiental ou correlatas, e na Tabela 2 - cursos que não possuem em sua matriz curricular disciplinas de cunho ambiental. 
Tabela 1 - Relação entre os cursos e as disciplinas de cunho ambiental

\begin{tabular}{|c|c|c|}
\hline $\begin{array}{l}47 \text { MODALIDADES DE } \\
\text { CURSOS }\end{array}$ & 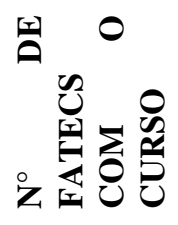 & $\begin{array}{c}\text { DISCIPLINAS DE RELACIONADAS A GESTÃO } \\
\text { AMBIENTAL }\end{array}$ \\
\hline Agroindústria & 1 & Meio Ambiente e Tratamento de Resíduos \\
\hline Agronegócio & 9 & Gestão Ambiental \\
\hline Banco de Dados & 2 & Tecnologia e Ambiente \\
\hline Biocombustíveis & 3 & Gestão Ambiental e Desenvolvimento Sustentável \\
\hline $\begin{array}{l}\text { Construção Civil - Movimento de } \\
\text { Terra e Pavimentação }\end{array}$ & 1 & Desenvolvimento. Sustentável \\
\hline Controle de Obras & 1 & Gestão Ambiental e da Qualidade na Construção Civil \\
\hline Cosméticos & 1 & Controle Ambiental \\
\hline Eletrônica Automotiva & 3 & Meio Ambiente \\
\hline Eletrônica Industrial & 1 & Direito Ambiental e Sustentabilidade \\
\hline Eventos & 6 & Gestão Ambiental em Eventos \\
\hline Gestão Ambiental & 3 & Gestão Ambiental e Sistema de Qualidade \\
\hline Gestão da Produção Industrial & 13 & Gestão Ambiental Aplicada \\
\hline $\begin{array}{l}\text { Gestão da Tecnologia da } \\
\text { Informação }\end{array}$ & 12 & Gestão Ambiental \\
\hline $\begin{array}{l}\text { Gestão de Energia e Eficiência } \\
\text { Energética }\end{array}$ & 2 & Energia e Ambiente \\
\hline Gestão de Negócios e Inovação & 3 & Ética e Responsabilidade socioambiental \\
\hline Gestão de Turismo & 2 & Aspectos Ambientais do Turismo \\
\hline Gestão Empresarial & 24 & Gestão Ambiental \\
\hline Gestão Portuária & 1 & Desenvolvimento Sustentável \\
\hline Hidráulica e Saneamento Ambiental & 1 & Gerenciamento ambiental \\
\hline Informática para Negócios & 3 & Gestão de Qualidade e Ambiental \\
\hline Instalações Elétricas & 1 & Sustentabilidade \\
\hline Logística Aeroportuária & 2 & Impactos Ambiental na Operação dos Transporte \\
\hline Manufatura Avançada & 3 & Meio Ambiental, Segurança e Sustentabilidade \\
\hline Manutenção de Aeronaves & 1 & Meio Ambiental, Saúde e Segurança no Trabalho \\
\hline Manutenção Industrial & 4 & Meio Ambiente e Segurança no Trabalho \\
\hline Marketing & 1 & Ética e Responsabilidade socioambiental \\
\hline Materiais & 1 & Atividades Minerais e Meio Ambiente \\
\hline Mecânica - Processos de Soldagem & 3 & Gestão Ambiental \\
\hline Mecânica Automobilística & 1 & Meio Ambiente \\
\hline $\begin{array}{l}\text { Mecanização em Agricultura de } \\
\text { Precisão }\end{array}$ & 1 & Ética Profissional e Meio Ambiente \\
\hline $\begin{array}{l}\text { Meio Ambiente e Recursos } \\
\text { Hídricos }\end{array}$ & 2 & Planejamento e Gestão Ambiental Urbana \\
\hline Microeletrônica & 1 & Direito Ambiental e Sustentabilidade \\
\hline Polímeros & 3 & Saneamento Ambiental \\
\hline Processos Metalúrgicos & 2 & Gestão Ambiental \\
\hline Processos Químicos & 2 & Gestão Ambiental \\
\hline Produção Agropecuária & 1 & Gestão Ambiental e Recursos Hídricos \\
\hline Produção Industrial & 3 & Gestão Ambiental \\
\hline Produção Têxtil & 1 & Gestão Ambiental \\
\hline Projetos de Estruturas Aeronáuticas & 1 & Saneamento Ambiental \\
\hline Projetos Mecânicos & 3 & Gestão Ambiental Industrial \\
\hline Redes de Computadores & 3 & Tecnologia e Ambiente \\
\hline
\end{tabular}




\section{(II) SITEFA}

\begin{tabular}{l|c|l}
\hline $\begin{array}{l}\text { Refrigeração, Ventilação e Ar } \\
\text { Condicionado }\end{array}$ & $\mathbf{1}$ & Eficiência Energia de Sistema Térmico e Meio ambiente \\
\hline Silvicultura & $\mathbf{1}$ & Recuperação de áreas degradadas e EIA \\
\hline Sistemas Navais & $\mathbf{1}$ & Gestão Ambiental de Terminais e Portos \\
\hline Soldagem & $\mathbf{1}$ & Gestão Ambiental na Soldagem \\
\hline Têxtil e Moda & $\mathbf{1}$ & Gestão Ambiental \\
\hline Transporte Terrestre & $\mathbf{2}$ & Impactos Ambientais da Operação dos Transporte \\
\cline { 1 - 2 } \multicolumn{1}{c|}{ Total } & $\mathbf{1 3 9}$ &
\end{tabular}

Fonte: elaborada pelos autores (2019) - com fundamento na estrutura curricular dos cursos das FATECs. (PORTAL CENTRO PAULA SOUZA, 2019)

Verificando-se a Tabela 1 vê-se que $47(61,0 \%)$ das modalidades de cursos já possuem disciplinas relacionadas a gestão ambiental e que estas modalidades correspondem a $139(50,9 \%)$ cursos oferecidos nos campi da FATEC distribuídos pelo estado de São Paulo.

Tabela 2 - Cursos sem disciplinas de cunho ambiental

\begin{tabular}{|c|c|c|}
\hline 30 MODALIDADES DE CURSOS & 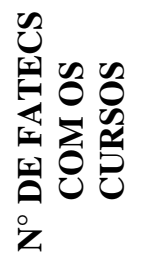 & $\begin{array}{c}\text { DISCIPLINAS DE RELACIONADAS A } \\
\text { GESTÃO AMBIENTAL }\end{array}$ \\
\hline Alimentos & 2 & Não possui \\
\hline Análise de Processos Agroindustriais & 1 & Não foi possível obter informações \\
\hline Análise e Desenvolvimento de Sistemas & 36 & Não possui \\
\hline Automação de Escritórios e Secretariado & 1 & Não possui \\
\hline Automação Industrial & 6 & Não possui \\
\hline Big Data no Agronegócio & 1 & Não possui \\
\hline Comércio Exterior & 7 & Não possui \\
\hline Construção Civil - Edifícios & 1 & Não possui \\
\hline Construção de Edifícios & 1 & Não possui \\
\hline Construção Naval & 1 & Não possui \\
\hline Desenvolvimento de Produtos Plásticos & 2 & Não possui \\
\hline Design de Mídias Digitais & 2 & Não possui \\
\hline Fabricação Mecânica & 4 & Não possui \\
\hline Geoprocessamento & 1 & Não possui \\
\hline Gestão Comercial & 8 & Não possui \\
\hline Gestão de Recursos Humanos & 7 & Não possui \\
\hline Gestão de Serviços & 1 & Não possui \\
\hline Gestão Financeira & 3 & Não possui \\
\hline Jogos Digitais & 4 & Não possui \\
\hline Logística & 19 & Não possui \\
\hline Mecânica - Processos de Produção & 1 & Não possui \\
\hline Mecânica - Projetos & 1 & Não possui \\
\hline Mecânica de Precisão & 1 & Não possui \\
\hline Mecatrônica Industrial & 5 & Não possui \\
\hline Produção Fonográfica & 1 & Não possui \\
\hline Radiologia & 1 & Não possui \\
\hline Secretariado & 2 & Não possui \\
\hline Segurança da Informação & 4 & Não possui \\
\hline
\end{tabular}




\section{(ii) SinEF}

\begin{tabular}{c|c|c}
\hline Sistemas Biomédicos & $\mathbf{3}$ & Não possui \\
\hline Sistemas para Internet & $\mathbf{7}$ & Não possui \\
\hline Total & $\mathbf{1 3 4}$ &
\end{tabular}

Fonte: elaborada pelos autores (2019) - com fundamento na estrutura curricular dos cursos das

FATECs. (PORTAL CENTRO PAULA SOUZA, 2019)

Verificando-se a Tabela 2 observa-se que $30(39,0 \%)$ das modalidades de cursos não possuem disciplinas relacionadas a gestão ambiental e estas correspondem a $134(49,1 \%)$ cursos oferecidos nos campi da FATEC distribuídos pelo estado de São Paulo.

Embora, uma quantidade maior de modalidades de cursos, já se enquadram nos termos descritos na Lei 9.795/1999 da Política Nacional de Educação Ambiental o número de alunos que recebem estas informações ambientais são aproximadamente metade dos egressos das unidades da FATEC, pois a distribuição dos números de cursos que apresentam e não apresentam as disciplinas de gestão ambiental estão aproximadamente na mesma proporção. O Gráfico 1 mostra a comparação identificadas nas Tabela 1 e Tabela 2.

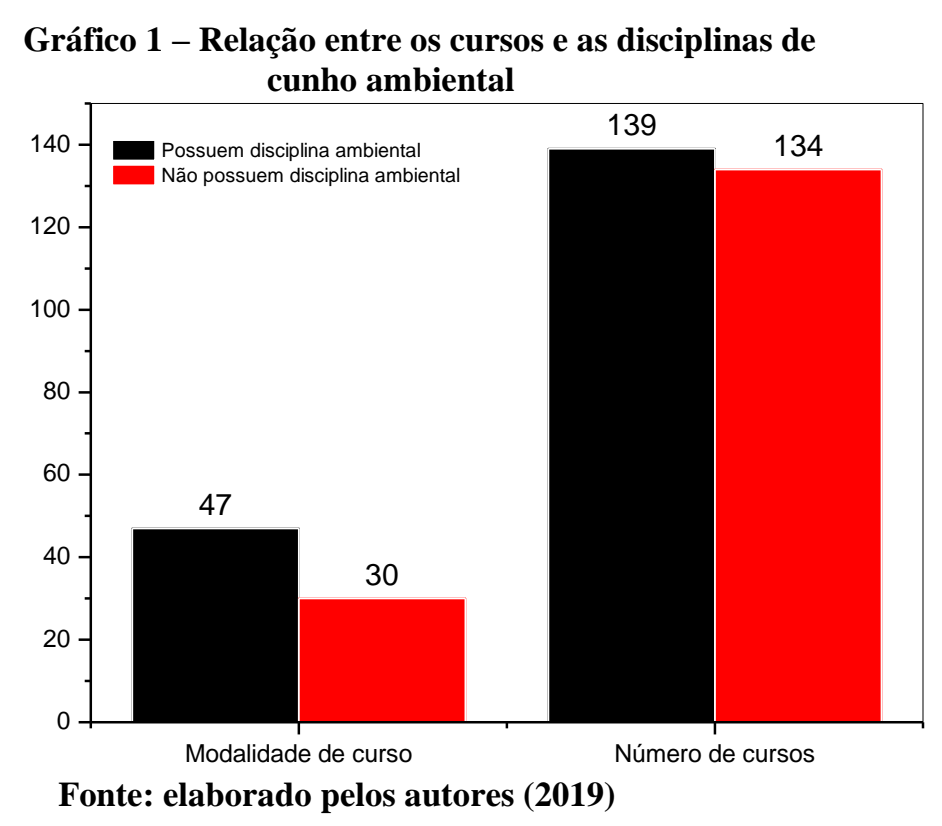

Em relação aos eixos temáticos dos cursos da FATEC observa-se os dados identificados na Tabela 3.

Tabela 3 - Relação entre os eixos temáticos

\begin{tabular}{l|c|c|c}
\hline EIXOS TEMÁTICOS & & & \\
& 22 & 16 & 6 \\
\hline Produção Alimentícia & 2 & 1 & 1 \\
\hline Recursos Naturais & 2 & 3 & 0 \\
\hline Controle e Processos Industriais & 2 & & \\
\hline
\end{tabular}




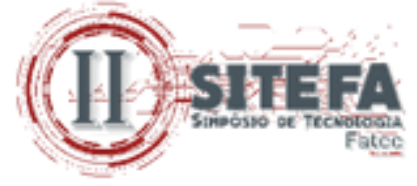

\begin{tabular}{l|c|c|c}
\hline Informação e Comunicação & 11 & 5 & 6 \\
\hline Produção industrial & 11 & 8 & 3 \\
\hline Infraestrutura & 7 & 4 & 7 \\
\hline Hospitalidade e Lazer & 2 & 2 & 0 \\
\hline Ambiente e saúde & 5 & 2 & 3 \\
\hline Gestão e Negócios & 13 & 5 & 8 \\
\hline Produção Cultural e Design & 1 & 0 & 1 \\
\hline
\end{tabular}

Fonte: elaborada pelos autores (2019) - com fundamento na estrutura curricular dos cursos das FATECs. (PORTAL CENTRO PAULA SOUZA, 2019)

O Gráfico 2 apresenta para cada eixo temático as quantidades de cursos que possuem e não possuem disciplinas de gestão ambiental.

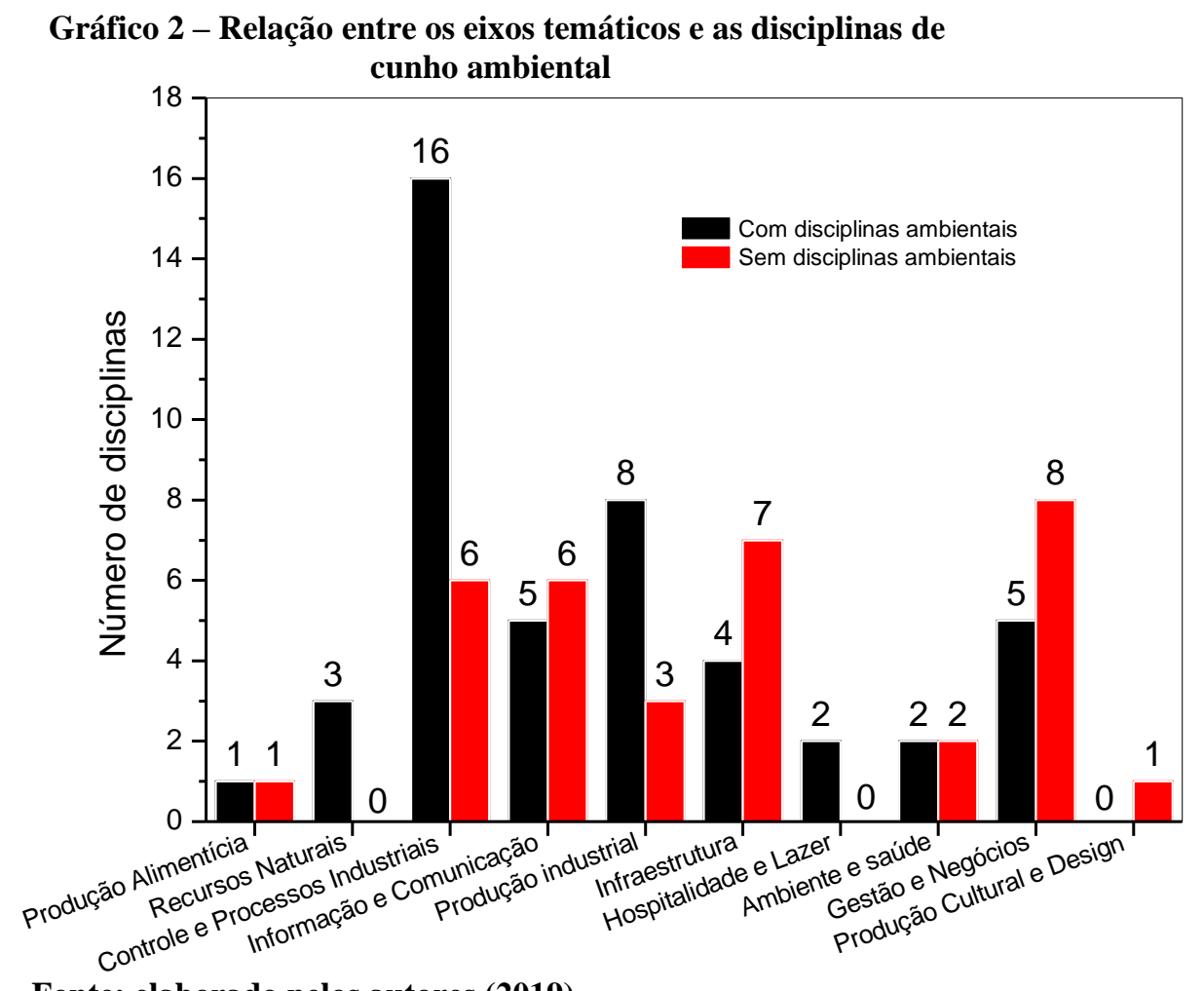

Fonte: elaborado pelos autores (2019)

Nota-se pelo Gráfico 2 que os eixos de controle e processos industriais e produção industrial são os que proporcionalmente apresentam mais possuem disciplinas ambientais, (72,7\% em ambos), mesmo assim (27,3\% em ambos) não possuem. Também se observa que dos 10 eixos temáticos 4 deles: informação e comunicação, infraestrutura, gestão de negócios e produção cultural e design, possuem mais disciplinas sem a abordagem da gestão ambiental.

As atividades dos egressos de todos os eixos temáticos normalmente são geradoras de impactos ambientais necessitando que disciplinas desta temática seja necessária na formação dos alunos. Uma atenção especial ao eixo de gestão de negócios, pois com a atual abordagem 


\section{(II) SITEFA}

da sustentabilidade em todos os negócios não se justifica que a maioria de seus cursos não terem nenhuma disciplina que de ênfase na gestão ambiental.

A nuvem de palavras contidas nos ementários das disciplinas de gestão ambiental e correlatas identificadas são apresentadas na Figura $1 \mathrm{com}$ a respectiva Tabela $4 \mathrm{com}$ as palavras mais citadas.

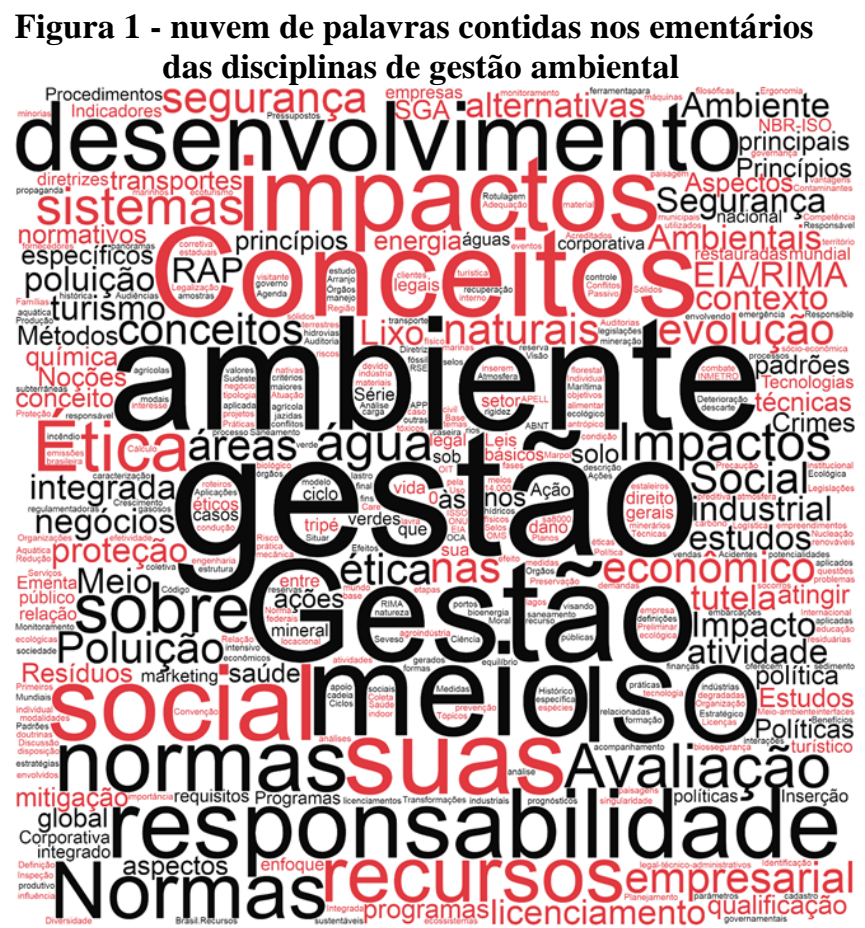

Fonte: elaborada pelos autores (2019)

A Tabela 4 apresenta o número de citações das 15 palavras mais citadas nas ementas das disciplinas de gestão ambiental e correlatas observadas.

Tabela 4 - Palavras mais citadas nas ementas das disciplinas ambientais

\begin{tabular}{c|l|c}
\hline $\mathbf{N}^{\mathbf{0}}$ & \multicolumn{1}{c|}{ PALAVRAS } & CITAÇ ÕES \\
\hline 1 & Ambiental & 167 \\
\hline 2 & Gestão & 49 \\
\hline 3 & Meio & 25 \\
\hline 4 & Conceitos & 21 \\
\hline 5 & Normas & 19 \\
\hline 6 & Impactos & 18 \\
\hline 7 & Desenvolvimento & 17 \\
\hline 8 & Social & 17 \\
\hline 9 & Responsabilidade & 16 \\
\hline 10 & Sistemas & 15 \\
\hline 11 & Certificação & 14 \\
\hline 12 & Legislação & 14 \\
\hline 13 & Ética & 13 \\
\hline
\end{tabular}




\begin{tabular}{l|l|c}
\hline 14 & ISO 14001 & 13 \\
\hline 15 & Sustentabilidade & 12 \\
\hline
\end{tabular}

Fonte: elaborado pelos autores (2019)

Por esta análise observa-se que as disciplinas dos cursos que abordam a gestão ambiental apresentam uma grande variedade de termos relacionados ao tema, esta variabilidade se justifica pelo fato do próprio número de cursos, cada qual com suas especificidades.

\section{CONSIDERAÇÕES FINAIS}

Após os resultados observados, conclui-se que $61 \%$ das modalidades dos cursos ministrados na FATEC atualmente possuem pelo menos uma disciplina relacionada à gestão ambiental contra $39 \%$ de modalidades que não possuem disciplinas relacionadas à gestão ambiental, porém quando se trata da quantidade de cursos sendo ministrados em todos os campi da FATEC, os números tendem a se dividirem igualmente, pois $50,9 \%$ possuem e 49,1\% não possuem disciplinas relacionadas à gestão ambiental.

Isto indica que a metade dos cursos procurados e ministrados nos campi da FATEC não possuem disciplinas na área de gestão ambiental, o que representa um contra senso, pois a procura por formação em tais cursos deve-se, por estar mais associados com as atuais tendências do mercado de trabalho o que é uma característica dos cursos oferecidos pela FATEC.

A gestão ambiental é algo atual e presente na preocupação da sociedade, clientes e consumidores, pois está diretamente relacionada com as questões ambientais, sociais e econômicas do mundo contemporâneo. Assim não se explica o porquê os cursos que buscam ministrar em sua formação as tendências atuais do mercado não possuírem em sua grade disciplinas de gestão ambiental e outras disciplinas relacionadas.

Os eixos industriais, por sua vez, englobam atividades profissionais que possuem um maior potencial de provocar impactos ao ambiente e por isso se justificaria a necessidade de abordar tais tópicos em sua formação acadêmica.

O estudo mostrou que ainda há muito que se fazer para que a temática ambiental tenha sua devia importância na formação dos tecnólogos formados pela FATEC e também apresentou algumas dificuldades na obtenção das informações, pois algumas unidades não possuem nos websites informações das grades de disciplinas e ementários destas.

\section{REFERÊNCIAS}

ABNT NBR ISO 14001:2015 Sistemas de Gestão Ambiental - Requisitos com Orientações para Uso. 06/11/2015.

BARBIERI, José Carlos. Gestão ambiental empresarial: conceitos, modelos e instrumentos. 3.ed. rev. e atual. São Paulo: Saraiva, 2016.

BARBIERI, José Carlos. A educação ambiental e a gestão ambiental em cursos de graduação em administração: objetivos, desafios e propostas. Revista de Administração Pública, Rio de Janeiro, v. 38, n. 6, p. 919 a 946, jan. 2004. ISSN 1982-3134. Disponível em: http://bibliotecadigital.fgv.br/ojs/index.php/rap/article/view/6766. Acesso em: 08 Set. 2019. 


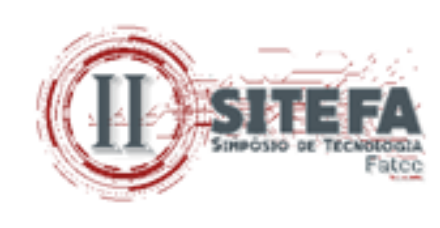

BRASIL. Política Nacional de Educação Ambiental, Lei 9.795. Diário Oficial da República Federativa do Brasil, Brasília, DF: 27 abr. 1999. Disponível em: http://www.planalto.gov.br/ ccivil_03/Leis/L9795htm. Acesso em: 18 jun. 2019.

DRUZZIAN, E. T. V.; SANTOS, R. C. Sistema de gerenciamento ambiental (SGA): buscando uma resposta para os resíduos de laboratórios das instituições de ensino médio e profissionalizante. Revista Liberato, Rio Grande do Sul, vol. 7, pp. 40 - 44, 2006.

FERNANDES, Fábio. Meio ambiente geral e meio ambiente do trabalho: uma visão sistêmica. São Paulo: LTr. 2009.

MOREIRA, Maria Suely. Estratégia e implantação do sistema de gestão ambiental (modelo ISO 14001) Referência: versão 2004 da NBR ISSO 14001. 4. ed., Minas Gerais: Falconi, 2013.

MAYOR, F. Preparar um futuro viável: ensino superior e desenvolvimento sustentável. In: Conferência mundial sobre o ensino superior. Tendências de educação superior para o século XXI. Anais da Conferência Mundial do Ensino Superior. Paris: 1998.

MOURA, Luiz Antônio Abdalla de. Qualidade e gestão ambiental: sustentabilidade e implantação da ISO 14.001. 6.ed. rev. e atual. São Paulo: Juarez de Oliveira, 2011.

PORTAL CENTRO PAULA SOUZA. Informações sobre os cursos. Disponível em: http://www.portal.cps.sp.gov.br/cursos/fatec/. Acesso em: 02 jul. 2019

RODRIGUES, C. R. B.; OLIVEIRA, I. L.; PILATTI, L. A. Abordagem dos resíduos sólidos de serviços de saúde na formação acadêmica em cursos da área da saúde. In: Congresso Internacional de Administração, Gestão Estratégica para o desenvolvimento sustentável, 17 a 21 de setembro, Ponta Grossa, 2007.

SEIFFERT, Mari Elizabete Bernardini. Gestão ambiental: instrumentos, esferas de ação e educação ambiental. 8 ed, São Paulo: Atlas, 2014.

TACHIZAWA, Takeshy. Gestão ambiental e responsabilidade social corporativa: estratégias de negócios focadas na realidade brasileira. 8 ed. São Paulo: Atlas, 2015. 